\title{
Effect of dietary fibre mixture on growth and intestinal iron absorption in rats recovering from iron-deficiency anaemia
}

\author{
Thabata Koester Weber, Karine de Cássia Freitas, Olga Maria Silvério Amancio \\ and Mauro Batista de Morais* \\ Pediatric Gastroenterology Department, Federal University of Sao Paulo (UNIFESP), Rua Pedro de Toledo, 441, CEP 04039-031 \\ Sao Paulo-SP, Brazil
}

(Received 4 September 2009 - Revised 25 May 2010 - Accepted 26 May 2010 - First published online 6 August 2010)

There is concern regarding the possible negative effects of ingestion of dietary fibre on growth and intestinal Fe absorption in infants. The aim of the present study was to compare the effect of a fibre mixture on the growth and the intestinal absorption of Fe in rats with Fe-deficiency anaemia with that of a diet without fibres. Faecal weight and caecal $\mathrm{pH}$ were also evaluated. According to the Hb depletion-repletion model, twenty-two male weaned Wistar rats were fed the AIN93-G diet without Fe until Fe-deficiency anaemia was induced with $\mathrm{Hb}<70 \mathrm{~g} / \mathrm{l}$. The anaemic rats were divided into two groups: (1) fibre mixture group - fed $100 \mathrm{~g}$ of fibre mixture/kg of diet (soya polysaccharide, inulin, resistant starch, Arabic gum, fructooligossaccharide and cellulose) ( $n$ 11); (2) control group - fed without fibres $(n$ 11). All diets had $157 \mathrm{mg}$ of ferric citrate (30 mg of elemental Fe) added to lead to recovery from anaemia. Fe intestinal absorption was measured by Hb repletion efficiency (HRE) and apparent Fe intestinal absorption. The HRE was 44.8 (SD 9.5) \% in the fibre mixture group and 43.0 (SD 9.5) \% in the control group $(P=0.664)$. The apparent Fe absorption was 46.2 (SD 16.5) and $47.2(\mathrm{SD} \mathrm{10.2)} \%(P=0.861)$ in the fibre mixture and control groups, respectively. The faecal weight median was $6.17 \mathrm{~g}$ in the fibre mixture group and $2.11 \mathrm{~g}$ in the control group $(P<0 \cdot 001)$. The caecal pH was in the same order: 6.11 (SD 0.59) and 7.07 (SD 0.34) (P<0.001). Both the groups consumed similar quantities of diet, and growth was similar in both the groups. The fibre mixture had no influence either on growth or on $\mathrm{Fe}$ intestinal absorption in rats recovering from anaemia. This mixture favoured an increase in faecal weight and a decrease in caecal $\mathrm{pH}$.

Dietary fibre: Growth: Iron absorption: Iron-deficiency anaemia: Rats

Dietary fibres, in accordance with their type, can be fermented to different degrees in the different segments of the colon ${ }^{(1)}$. The fibre fermentation results in the formation of SCFA that reduce the intestinal $\mathrm{pH}$, bringing about greater solubility of minerals and an increase in peristalsis ${ }^{(2)}$. From a clinical point of view, it is believed that dietary fibres can reduce the risk of chronic diseases such as diabetes, CVD, obesity, cancer and intestinal constipation ${ }^{(3)}$.

Intestinal constipation occurs with elevated prevalence in unweaned infants ${ }^{(4)}$. The start of the symptoms is associated with the introduction of complementary foods, including lacteal formulae ${ }^{(5)}$. Studies indicate that children with chronic constipation consume less dietary fibres than healthy children ${ }^{(6)}$. In this manner, low dietary fibre consumption is considered a risk factor for chronic constipation, and, to this end, a diet rich in dietary fibres is considered not only a preventative measure against the development of constipation, but also a part of the treatment $^{(7,8)}$.

The recommendations for the consumption of dietary fibres (American Health Foundation and Dietary References Intakes) do not take into consideration the first year of life due to the possible negative effects that the fibres can have about on growth and the absorption of minerals ${ }^{(9,10)}$, including $\mathrm{Fe}$.
Fe deficiency shows an elevated prevalence in unweaned infants, and can bring about Fe-deficiency anaemia and other repercussions, among which is the deficit in neuropsychomotor development ${ }^{(11-13)}$.

The majority of the studies that evaluated the effects of fibres on the bioavailability of $\mathrm{Fe}$ in the intestine are based on a single test meal ${ }^{(14)}$, apparent absorption ${ }^{(15,16)}$, or in vitro methods ${ }^{(17,18)}$ with results that are not always in agreement. On the other hand, bioavailability and the intestinal absorption of Fe, as well as food intake and weight gain, can be evaluated in a long-term basis by the way of regeneration of $\mathrm{Hb}$ in rats, with $\mathrm{Fe}$ anaemia in the growth phase with prior induced Fe-deficiency anaemia ${ }^{(19-21)}$.

Based on the theoretical principle that diet contains different types of fibres that are fermented to different levels in the colon, with a potential increase in the beneficial effect of dietary fibres, the food manufacturers formulated a supplement with six different types of fibres with proportions that approximate to that proclaimed in an ideal diet ${ }^{(22)}$. The beneficial effects of this fibre mixture in the prevention of constipation were observed in patients who consumed an enteral diet ${ }^{(23,24)}$. On the other hand, whether or not this fibre mixture can have an influence on Fe absorption, food intake and growth was not evaluated. 
Thus, the present study was carried out with the objective of evaluating whether or not a fibre mixture with $32.0 \%$ of soya polysaccharides, $12.5 \%$ inulin, $9.0 \%$ resistant starch, $24.0 \%$ Arabic gum, $10.5 \%$ fructo-oligosaccharides and $12.0 \%$ cellulose interferes with the intestinal absorption of $\mathrm{Fe}$, food intake and growth of anaemic rats during their growth phase. The biological effects of this mixture on the caecal $\mathrm{pH}$ and weight and faecal humidity were also evaluated.

\section{Experimental methods}

\section{Animals and experimental design}

A total of twenty-two male Wistar rats weaned at $21 \mathrm{~d}$, with 55.35 (SD 4.25) g mean body weight, from the laboratory animal house (Experimental Model Development Center) at the Federal University of Sao Paulo (Brazil) were used for the present experiment.

During the whole study period, the rats received ad libitum deionised water (MilliQ Plus system, Millipore Corporation, Sao Paulo, SP, Brazil) and rations. They were kept in individual metabolic cages (Nalgene Metabolic Cages 650-0100, Rochester, NY, USA), under a $12 \mathrm{~h}$ light cycle, at a temperature of $23 \pm 1{ }^{\circ} \mathrm{C}$.

The experimental study was divided into two phases to perform the rat model depletion-repletion methods. In the first phase, Fe-deficiency anaemia was induced. In the second phase, the effects of the fibre mixture on Fe bioavailability were evaluated. The study protocol was approved by the Research Ethics Committee of the Federal University of Sao Paulo, and was conducted in compliance with the International Guiding Principles for Biomedical Research Involving Animals (Council for International Organisations of Medical Sciences) - Geneva, 1985.

\section{Induction of Fe-deficiency anaemia}

To induce Fe-deficiency anaemia, the rats were fed the AIN93-G diet without Fe addition, as recommended by the American Institute of Nutrition ${ }^{(25)}$, for 2 or 3 weeks until they became anaemic, with $\mathrm{Hb}$ lower than $70 \mathrm{~g} / \mathrm{l}$; this was done to use the rat depletion-repletion model methods ${ }^{(26)}$. Following the induction of Fe-deficiency anaemia, the rats were randomised into two similar groups according to weight, length, $\mathrm{Hb}$ level, packed cell volume and number of weeks necessary to obtain $\mathrm{Hb}$ lower than $70 \mathrm{~g} / \mathrm{l}$. Therefore, fourteen rats were randomised after 2 weeks and eight rats after 3 weeks, a total of twenty-two rats with eleven in each group.

\section{Experimental diets}

The experimental diets (AIN93-G, modified) were offered to the anaemic rats for 3 weeks in each group: (1) fibre mixture group: $50 \mathrm{~g}$ of cellulose/kg of AIN93-G was replaced with $100 \mathrm{~g}$ of a dietary fibre mixture composed of $32.0 \%$ soya polysaccharide, $12.5 \%$ inulin, $9.0 \%$ resistant starch, $24.0 \%$ Arabic gum, $10.5 \%$ fructo-oligosaccharides and $12.0 \%$ cellulose (Stimulance multi-fibre; Milupa, Fulda, Germany, and imported and distributed by Support, Brazil); (2) control group: the $50 \mathrm{~g}$ of cellulose $/ \mathrm{kg}$ of AIN93-G was replaced with $100 \mathrm{~g}$ of maize starch/kg of feed, as suggested in the literature ${ }^{(27)}$. In both the groups, similar quantities of elemental Fe were added to the feeds $(30 \mathrm{mg} / \mathrm{kg}$ of diet) in the form of hydrated ferric citrate (Merck $^{\circledR}$, Frankfurt, Hesse, Germany). To increase the sensitivity of the model for the evaluation of the recovery $\mathrm{Hb}$ mass, $\mathrm{Fe}$ was offered at a quantity that was less than the recommendation for AIN93-G (35 mg/kg of ration), which allowed for the identification of even slightly poor Fe absorption, as reported previously ${ }^{(19-21)}$.

To produce the feed given to the fibre mixture group, the quantity of dietary fibre mixture was subtracted from the total of maize starch contained in the AIN93-G diet. The diets were prepared in the Research Laboratory of the Pediatrics Department, Federal University of Sao Paulo, Brazil. The diet compositions are given in Table 1.

\section{Evaluation of growth and $\mathrm{Hb}$ recovery}

After the start of the experimental diets, the weight and length of each rat were measured weekly. The rats were weighed on an electronic digital balance (CG LIBROR L-600; CG Instrumentos Científicos Limited, São Paulo, SP, Brazil) with a maximum capacity of $600 \mathrm{~g}$ and a sensitivity of $0 \cdot 1 \mathrm{~g}$. The length expressed in $\mathrm{cm}$ was measured using the technique described by Hugues \& Tanner $^{(28)}$, and it was obtained by summing the measures of the body and tail. A blood sample was collected from the tail to determine $\mathrm{Hb}$ and packed cell volume levels. $\mathrm{Hb}$ was determined by the cyanomethahaemoglobin method and microhaematocrit by the Wintrobe method (Perkin Elmer, model Victor3 1420 - 012 Wallac, Turku, Finland) ${ }^{(29)}$. Hb repletion efficiency (HRE) was determined according to the following formula ${ }^{(26,30)}$ :

$\mathrm{HRE}=(($ final total body $\mathrm{Hb} \mathrm{Fe}(\mathrm{mg})-$ initial total body $\mathrm{Hb} \mathrm{Fe}(\mathrm{mg})) /($ total Fe intake $(\mathrm{mg})) \times 100$.

Table 1. Composition of the AIN93-G diet, prepared in the laboratory, modified by the substitution of cellulose with either the fibre mixture or maize starch (control diet) and a reduction in the level of iron (30 mg/kg diet)

\begin{tabular}{lcc}
\hline $\begin{array}{l}\text { Ingredients } \\
(\mathrm{g} / \mathrm{kg})\end{array}$ & $\begin{array}{c}\text { Fibre mixture group } \\
(n 11)\end{array}$ & $\begin{array}{c}\text { Control group } \\
(n 11)\end{array}$ \\
\hline Maize starch & 447.89 & 579.49 \\
Cellulose & 0.00 & 0.00 \\
Fibre mixture & 131.60 & 0.00 \\
Casein & 195.52 & 200.00 \\
Sugar & 100.00 & 100.00 \\
Soya oil & 69.58 & 70.00 \\
L-Cystine & 3.00 & 3.00 \\
Choline bitartrate & 2.50 & 2.50 \\
$t$-Butyl hydroquinone & 0.014 & 0.014 \\
Vitamin mixture (Roche $\left.{ }^{\circledR}\right)^{\star}$ & 10.00 & 10.00 \\
Mineral mixture (Roche $\left.{ }^{\circledR}\right) \dagger$ & 35.00 & 35.00 \\
Ferric citrate (19\%) & 0.1572 & 0.1572 \\
\hline
\end{tabular}

Macronutrient and micronutrient composition of the fibre mixture/100 g: carbohydrate $11.8 \mathrm{~g}$; proteins $3.4 \mathrm{~g}$; total fats $0.32 \mathrm{~g}$; Ca $300 \mathrm{ng}$; $\mathrm{Fe} 0 \mathrm{mg}$; $\mathrm{Na} 60 \mathrm{mg}$;

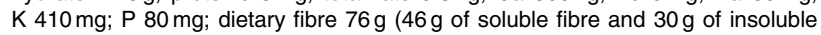
fibre).

* Composition in mg: nicotinic acid 30: pantothenate 15: pyridoxine 6: thiamin 5; riboflavin 6; folic acid 2. Composition in $\mu \mathrm{g}$ : vitamin $\mathrm{K} 750$; D-biotin 200; vitamin $B_{12} 25$. Composition in IU: vitamin A 4000; vitamin $D_{3} 1000$; vitamin E 75

† Composition in mg (essential minerals): Ca 5000; P 1561; K 3600; S 300; $\mathrm{Na}$ 1019; Cl 1571; Mg 507; Zn 30; Mn 10; Cu 6; iodine 0.2; Mo 0.15; Se 0.15; Si 5; Cr 1; fluoride 1; Ni 0.5; B 0.5; Li 0.1; V 0.1; with no iron. 
Total body $\mathrm{Hb} \mathrm{Fe}$ content was calculated using the following formula:

$\mathrm{Hb} \mathrm{Fe}(\mathrm{mg})=($ body weight $(\mathrm{g}) \times 0.075 \mathrm{ml} \mathrm{blood} / \mathrm{g}$ body weight $) \times(\mathrm{Hb}(\mathrm{g} / \mathrm{ml})) \times(3.35 \mathrm{mg} \mathrm{Fe} / \mathrm{Hb}(\mathrm{g}))$.

The amount of experimental diets consumed was measured daily. This allowed for the calculation of the weekly and total feed efficiency, which indicates how much of the ration is responsible for the weight gain of the rats. The feed efficiency was calculated using the following formula ${ }^{(31)}$ :

Feed efficiency $=($ weight gain $(\mathrm{g}) /$ consumption of diet $(\mathrm{g}))$.

\section{Apparent absorption of iron, fresh weight and faecal humidity}

During the last week of the experiment, $0 \cdot 1 \mathrm{~g}$ of carmine-pink dye (Merck ${ }^{\circledR}$, Frankfurt, Hesse, Germany) was added to the diets of each rat and the faeces excreted were collected for three consecutive days, beginning from the point at which the faeces became red. About $72 \mathrm{~h}$ after the addition of carmine-pink, another dye (aniline blue, soluble in water, INLAB, Sao Paulo, SP, Brazil) was added to the diets. Faeces collection was terminated when blue-coloured faeces were first excreted.

The faeces collected during the $3 \mathrm{~d}$ were stored in a freezer $\left(-20^{\circ} \mathrm{C}\right)$. After the third day of faeces collection, the wet weight of the faeces was measured with an electronic analytical balance (Mettler Toledo model AB204, Greisensee, Zürich, Switzerland), with a sensitivity of $0.1 \mathrm{mg}$. The faeces were then dried in an oven at $105^{\circ} \mathrm{C}$. After $22 \mathrm{~h}$, the faeces were weighed at $30 \mathrm{~min}$ intervals, until a constant weight was obtained. The faecal humidity was calculated according to the formula ${ }^{(20,32)}$ :

Fresh faecal weight - dry faecal weight/fresh faecal weight $\times 100$.

On the same analytical electronic balance, we measured, in a sequence, $500 \mathrm{mg}$ of dry faeces from each rat, which had been divided into two samples of $250 \mathrm{mg}$ (duplicate) and subjected to acid digestion with both nitric acid $(65 \%)$ and perchloric acid $(70 \%)$. The Fe content $(\mu \mathrm{g} / \mathrm{g}$ dry faeces) was then analysed in an atomic absorption spectrophotometer (model Perkin-Elmer - 5100 PC, Norwald, CT, USA) ${ }^{(33)}$. During the same period that the faeces were collected, the quantity correspondent to the Fe ingested $(\mu \mathrm{g})$ and excreted was also estimated.

To calculate the percentage of apparent absorption of $\mathrm{Fe}$, the following formula was applied ${ }^{(20)}$ :

\section{Quantity of Fe ingested $(\mu \mathrm{g})$}

- quantity of Fe excreted $(\mu \mathrm{g})$ / quantity of Fe ingested $(\mu \mathrm{g})$

$\times 100$.

The total quantity of Fe excreted was calculated according to the relation between $\mathrm{Fe}$ content in dry faeces and total dry faecal weight using the following formula: Fe excreted, $\mu \mathrm{g}=((\mathrm{Fe}(\mu \mathrm{g}) \times$ total dry faecal weight $(\mathrm{g})) / 1 \mathrm{~g}$ of dry faeces $(\mathrm{g}))$.

\section{Evaluation of hepatic iron and caecal $\mathrm{pH}$}

After 3 weeks of the dietary treatment, the rats were killed and their livers and caecums were extracted.

The fresh livers were weighed in an analytical balance (Metler Toledo model AB204) with a sensitivity of $0 \cdot 1 \mathrm{mg}^{(19-21)}$. The hepatic $\mathrm{Fe}$ was also determined after liquid digestion of the dried tissue with nitric and perchloric acids, by means of spectrophotometry, similar to the method used for the faeces as described by Marks et al. ${ }^{(33)}$.

The $\mathrm{pH}$ of the material extracted from the caecum was checked using a $\mathrm{pH}$ meter (Micronal $\mathrm{pH}$ meter, B374, Sao Paulo, SP, Brazil) between 6.00 and 10.00 hours, when intestinal fermentation is most active ${ }^{(34)}$.

\section{Statistical analysis}

The results are expressed as means and standard deviations, medians and percentages, or the distributions of the variables. For the comparison of groups, Student's $t$ test was applied when the variables were normally distributed, and the Mann-Whitney test was applied when the variables were not normally distributed.

All statistical and graphic tests were performed with the program Jandel-Sigma Stat 3.1 (Jandel Corporation, San Rafael, CA, USA) ${ }^{(35)}$, and the null hypothesis was rejected at the $0.05(5 \%)$ level.

\section{Results}

\section{Baseline data}

The mean values for weight at the beginning of the dietary treatment after the induction of Fe-deficiency anaemia were 136.53 (SD 24.87) $\mathrm{g}$ for the rats in the fibre mixture group and 140.56 (SD 20.67) $\mathrm{g}$ for the rats in the control group $(P=0.683)$. The mean values for body length, body + tail, were $30.54(\mathrm{SD} 2 \cdot 28)$ and $30.41(\mathrm{SD} 2 \cdot 04) \mathrm{cm}(P=0.892)$, respectively. The mean values for $\mathrm{Hb}$ were 5.76 (SD 0.67) and $58.0(\mathrm{SD} 0.67) \mathrm{g} / \mathrm{l}(P=0.890)$, respectively. The mean packed cell volume values were $20 \cdot 27$ (SD 2.10) \% and 20.54 (SD 2.70) \% $(P=0.794)$, respectively. Consequently, the two groups studied were similar in their weight, length, $\mathrm{Hb}$ and packed cell volume values at the beginning of the fibre mixture or control diet intake. The values obtained for $\mathrm{Hb}$ and packed cell volume demonstrated that the diet was sufficient to induce anaemia in the rats ${ }^{(30,31)}$.

\section{Effect of fibre mixture on faecal weight and humidity and caecal $\mathrm{pH}$}

The medians (25th and 75th percentiles in parentheses) for the wet weight of the faeces collected over $3 \mathrm{~d}$ between days 17 and 19 of the experimental diets were $6.17(4.87-9.13) \mathrm{g}$ in the fibre mixture group and $2 \cdot 11(1.52-2 \cdot 39) \mathrm{g}$ in the control group, which were significantly different $(P<0.001)$. The faeces of the fibre mixtur group were more humid (39.41 (SD 20.24) \%) than those of the control group (29.58 (SD 13.83) \%), although the difference was not statistically significant $(P=0.199)$. The caecal $\mathrm{pH}$ was $6 \cdot 11$ (SD 0.59) for the fibre mixture group and 7.07 (SD 0.34 ) for the control group, which were significantly different $(P<0 \cdot 001)$. 


\section{Food intake and growth}

During the experiment, the rats in both the groups had similar weekly food intake, weights and lengths. The final body weight in the fibre mixture group was 265.16 (SD 19.35) g, and in the control group, it was 273.35 (SD 20.34) $\mathrm{g}$ $(P=0 \cdot 345)$. The final body lengths were 39.02 (SD 1.57) and 39.15 (SD 0.70$) \mathrm{cm} \quad(P=0.795)$, respectively. Thus, the relationship between weight gain and the weekly consumption of diet, representing the feed efficiency, was also similar between the groups. Table 2 shows the weekly food intake parameters for each group: total food intake $(\mathrm{g})$ and feed efficiency. There was no statistically significant difference between the groups.

\section{$\mathrm{Hb}$ recovery: apparent absorption of $\mathrm{Fe}$ and $\mathrm{Hb}$ repletion efficiency}

Table 2 shows the increase in the weekly values for $\mathrm{Hb}(\mathrm{g} / \mathrm{l})$ in the two groups after the start of the dietary treatment. The results demonstrate that the recovery from previously induced anaemia was similar in both the groups.

The mean values for packed cell volume during the first week in the fibre mixture and control groups were 27.91 (SD $2.39)$ and 27.54 (SD 3.11) \% $(P=0.761)$, respectively. During the second week, the values were 32.82 (SD 3.03) and $34.09(\mathrm{SD} 3 \cdot 21) \%(P=0 \cdot 350)$, respectively, and during the third week, they were 36.73 (SD 3.47) and 35.45 (SD $2.73) \%(P=0 \cdot 350)$, respectively.

The mean value for the apparent absorption of $\mathrm{Fe}$, which corresponds to the difference between the total Fe ingested and the total $\mathrm{Fe}$ excreted in the faeces, was similar in both the groups: 46.18 (SD 16.48) $\%$ in the fibre mixture group and 47.22 (SD 10.23) \% in the control group, which were not significantly different $(P=0 \cdot 861)$. The final mean value for the HRE did not differ between the two groups: 44.8 (SD 9.51) $\%$ in the fibre mixture group and 43.0 (SD 9.46) \% in the control group $(P=0 \cdot 664)$. Weekly data analysis (not shown) indicated that during 3 weeks of the present study, the fibre mixture effect on HRE was similar to that observed in the control group (Fig. 1).

\section{Hepatic iron}

The fresh weight of the liver was equal to $12 \cdot 81$ (SD 1.06) $\mathrm{g}$ in the fibre mixture group and 13.23 (SD 1.77) $\mathrm{g}$ in the control group $(P=0.514)$. The levels of hepatic $\mathrm{Fe}$ in the dry tissue of the fibre mixture and control groups were 188.73 (SD 42.31) and 172.18 (SD 58.02) $\mu \mathrm{g} / \mathrm{g}(P=0.454)$, respectively, which were not significantly different.

\section{Discussion}

The model used in the present study was adequate to show that the fibre mixture did not reduce Fe absorption, food intake and weight gain of the rats. A biological effect expected for this fibre mixture was observed, that is, a reduction of the caecal $\mathrm{pH}$ and an increase in the faecal volume were observed. In spite of the faecal humidity having been halved in the group that received the fibre mixture, statistical significance was not reached. Some of the effects of such a mixture on the gastrointestinal tract have been previously evaluated in human subjects ${ }^{(23,24)}$; nevertheless, the absorption of minerals was not evaluated.

The intestinal absorption of $\mathrm{Fe}$ was similar in the two groups, when evaluated both by the weekly HRE and by the balance of Fe carried out during the third week of the study. Both indicated bioavailability of approximately $45 \%$ of $\mathrm{Fe}$. It is worth emphasising that this is the only study in which the effect of this fibre mixture on mineral absorption was evaluated, demonstrating that this fibre mixture does not compromise the intestinal absorption of Fe.

Also, the analysed fibre mixture did not bring about a restriction of food intake and growth, as has been observed

Table 2. Data obtained from the weekly assessment of food intake $(\mathrm{g})$, feed efficiency $(\mathrm{g} / \mathrm{g})$ and $\mathrm{Hb}$ recuperation $(\mathrm{g} / \mathrm{l})$ of the rats of the fibre mixture and control groups

(Mean values and standard deviations, medians and percentiles (25th-75th))

\begin{tabular}{|c|c|c|c|c|c|}
\hline & \multicolumn{2}{|c|}{ Fibre mixture group ( $n 11)$} & \multicolumn{2}{|c|}{ Control group ( $n$ 11) } & \multirow[b]{2}{*}{$P$} \\
\hline & Mean/median & sD/percentiles & Mean/median & sD/percentiles & \\
\hline \multicolumn{6}{|l|}{ Food intake $(\mathrm{g})^{*}$} \\
\hline First week & $116 \cdot 64$ & $13 \cdot 68$ & 115.09 & $12 \cdot 09$ & 0.781 \\
\hline Second week & $124 \cdot 26$ & $10 \cdot 78$ & $129 \cdot 64$ & $11 \cdot 10$ & 0.262 \\
\hline Third week & 134.46 & $12 \cdot 63$ & $141 \cdot 22$ & $11 \cdot 10$ & 0.198 \\
\hline Total & $375 \cdot 37$ & 31.99 & 385.95 & 30.47 & 0.436 \\
\hline \multicolumn{6}{|c|}{$\mathrm{Hb}$ recuperation $(\mathrm{g} / \mathrm{l})^{*}$} \\
\hline Basal & $57 \cdot 6$ & $6 \cdot 6$ & $58 \cdot 0$ & $7 \cdot 0$ & 0.890 \\
\hline First week & $75 \cdot 3$ & $8 \cdot 6$ & $70 \cdot 4$ & 8.9 & 0.205 \\
\hline Second week & $91 \cdot 2$ & $9 \cdot 3$ & 88.9 & $11 \cdot 1$ & 0.522 \\
\hline Third week & $105 \cdot 3$ & $14 \cdot 0$ & $101 \cdot 6$ & $11 \cdot 1$ & 0.504 \\
\hline \multicolumn{6}{|c|}{ Feed efficiency $(\mathrm{g} / \mathrm{g}) \dagger$} \\
\hline First week & 0.43 & $0.38-0.45$ & 0.41 & $0.37-0.43$ & 0.278 \\
\hline Second week & 0.36 & $0.31-0.39$ & 0.38 & $0.31-0.39$ & 0.646 \\
\hline Third week & 0.31 & $0.20-0.33$ & 0.29 & $0.24-0.34$ & 0.974 \\
\hline Total & $1 \cdot 11$ & $0.94-1.16$ & $1 \cdot 10$ & $0.93-1.16$ & 1.000 \\
\hline
\end{tabular}

* Student's $t$ test.

$\dagger$ Mann-Whitney test. 


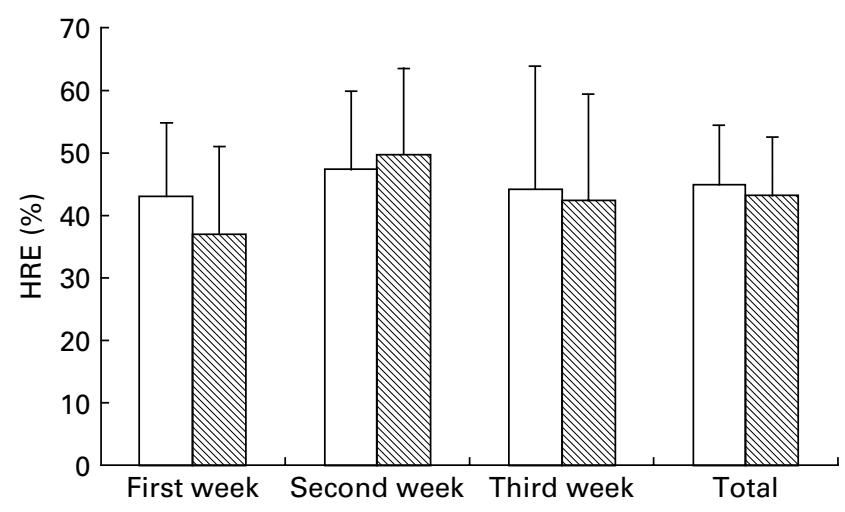

Fig. 1. Effects of fibre mixture on $\mathrm{Hb}$ repletion efficiency (HRE) in the fibre mixture and control groups. Data were analysed using Student's $t$-test. Values are means with their standard errors ( $n 11$ per group). There was no significant difference between the two groups during each week and total study period $(P>0.05)$. $\square$, Fibre mixture group; $\mathbb{\mathbb { N }}$, control group.

in previous studies with cellulose, wheat bran and guar gum $^{(19,20)}$. Feed efficiency was also considered in the present study, and it was identical for both the groups, which displayed no significant differences in the amount of diet consumed, weight gain, body length or fresh liver weight.

Thus, the non-existence of a negative effect of this fibre mixture on growth and Fe absorption must be confirmed in future studies on human infants by considering the importance of the introduction of dietary fibres in complementary foods to guarantee not only the maintenance of the normal intestinal rhythm, but also the development of a dietary habit in which the dietary fibres are in adequate quantity and quality.

Traditionally, insoluble fibre is considered to prejudice the absorption of minerals. However, the addition of soya polysaccharide $(32.0 \%)$ and cellulose $(12.0 \%)$ to the fibre mixture did not interfere with the absorption of $\mathrm{Fe}$, thus verifying the results of other studies ${ }^{(19,20,34,36)}$. The insoluble fibres, cellulose being one among them, which is fermented only slightly in the distal portions of the colon, have shown a great capacity to retain water, contributing to the faecal bulk and thus increasing the faecal volume ${ }^{(20)}$. The soya polysaccharide, despite being considered an insoluble fibre, is strongly fermented in a portion of the ascending colon, and also contributes substantially to the increase in the faecal weight and faecal humidity ${ }^{(32)}$. The fibres, when fermented, contribute to the increase in the faecal biomass, which is consistent with the increase in the faecal volume ${ }^{(37)}$.

The faecal analysis showed that the faecal weight was greater in the fibre mixture group than in the control group. The significant difference in the median weight of the fresh faeces collected over $3 \mathrm{~d}$ in both the groups may have been partially influenced by the addition of the insoluble fibres (soya polysaccharide and cellulose) to the mixture ${ }^{(32)}$. The faecal humidity values demonstrate that the fibre mixture generated a medium percentage of humidity, higher than that in the control group, although the difference was not statistically significant.

The increase in faecal weight and faecal humidity may be related to the increase in the rate of intestinal transit, as in the theory proposed by Burkitt ${ }^{(38)}$. Greater faecal volume is related to an increase in intestinal motility, whereas an increase in faecal humidity provides greater softness to the faeces. The addition of the fibre mixture to an enteral diet promoted a reduction in the intestinal transit time, measured with a radio-pack marker; however, no effect of the fibre mixture on faecal weight was observed in human subjects in a study conducted by Skil et al. ${ }^{(23)}$. In terms of the fermentation of the fibre mixture used in the present study, Schneider et al. ${ }^{(24)}$ observed that when the same mixture was fed to human subjects in an enteral diet, it promoted an increase in total SCFA production, especially butyrate, and an increase in the total bacterial score. In the present study, the reduction in the caecal $\mathrm{pH}$ and the increase in the caecal volume of the group that consumed the mixture suggest that the fibres underwent fermentation in the proximal portion of the colon, and that it had been maintained over the colon due to the different degrees of fermentation of the fibre mixture

In summary, the dietary fibre mixture supplement, containing six different types of fibres with different solubility and fermentability, did not interfere with the growth or Fe absorption of rats with Fe-deficiency anaemia in their growth phase, although it caused an increase in the faecal weight and humidity, and a reduction in the caecal $\mathrm{pH}$. Consequently, the consumption of this dietary fibre mixture had no negative nutritional effects in the rats evaluated. These preliminary findings in animal experiments must be confirmed in further studies involving human infants using appropriate methods for evaluation of intestinal Fe absorption.

\section{Acknowledgements}

This research was supported by 'Coordination of Improvement of Higher Education' - CAPES and the 'National Council of Technological and Scientific Development' - CNPq, Brazil. The authors thank Ms Roberta Faria Camilo Araújo and Mr Felipe Faria Pierotti for their excellent technical assistance and Support Advanced Medical Nutrition, Brazil, for providing the dietary fibre mixture, Stimulance ${ }^{\circledR}$. T. K. W., K. d. C. F., O. M. S. A. and M. B. M. worked on preparing the project design, data analysis, statistical study, final revision and submission of manuscript. T. K. W. and K. d. C. F. conducted the experiment with the animals and T. K. W. and O. M. S. A. performed the laboratorial analysis. The authors state that there are potential personal conflicts of interest since M. B. M. is a speaker for Support Advanced Medical Nutrition in Brazil.

\section{References}

1. Food and Nutrition Board (2001) Proposed definition of dietary fiber. In Food and Nutrition Board. Dietary Reference Intakes: Proposed Definition of Dietary Fiber. A Report of the Panel on the Definition of Dietary Fiber and the Standing Committee on the Scientific Evaluation of Dietary Reference Intakes, pp. 22-25. Washington, DC: National Academy Press.

2. Cummings JH (1984) Constipation, dietary fibre and the control of large bowel function. Postgrad Med J 60, 811-819.

3. Anderson JW, Smith BM \& Gustafson NJ (1994) Health benefits and practical aspects of high-fiber diets. Am J Clin Nutr 59, Suppl 1, S1242-S1247.

4. Van den Berg MM, Van Rossum CH, de Lorijin F, et al. (2005) Functional constipation in infants: a follow-up study. $J$ Pediatr 147, 700-704. 
5. Aguirre AN, Vitolo MR, Puccini RF, et al. (2002) Constipation in infants: influence of type of feeding and dietary fiber intake. J Pediatr (Rio J) 78, 2002-2008.

6. Morais MB, Vítolo MR, Aguirre ANC, et al. (1999) Measurement of low dietary fiber intake as a risk factor for chronic constipation in children. J Pediatr Gastroenterol Nutr 29, $132-135$

7. Baker SS, Liptak GS, Colletti RS, et al. (1999) Constipation in infants and children: evaluation and treatment. $J$ Pediatr Gastroenterol Nutr 29, 612-626.

8. NASPGHAN Constipation Guideline Committee (2006) Evaluation and treatment of constipation in infants and children: recommendation of North American Society for Pediatric and Gastroenterology, Hepatology and Nutrition. J Pediatr Gastroenterol Nutr 43, e1-e13.

9. Dwyer JT (1995) Dietary fiber for children: how much? Pediatrics 96, 1019-1022.

10. Agget PJ, Agostoni C, Axelsson I, et al. (2003) Nondigestible carbohydrates in the diets if infants and young children: a commentary by the ESPGHAN Committee on Nutrition. $J$ Pediatr Gastroenterol Nutr 36, 329-337.

11. World Health Organization (2002) The World Health Report 2002. Reducing Risks, Promoting Health. Geneva: WHO.

12. Aggett PJ, Agostoni C, Axelsson I, et al. (2002) Iron metabolism and requirements in early childhood: do we know enough? A commentary by the ESPGHAN Committee on Nutrition. J Pediatr Gastroenterol Nutr 34, 337-345.

13. Ziegler E, Vanderhoof JA, Petschow B, et al. (2007) Term infants fed formula supplemented with selected blends of prebiotics grow normally and have soft stools similar to those reported for breast-fed infants. J Pediatr Gastroenterol Nutr 44, 359-364.

14. Simpson KM, Morris ER \& Cook JD (1981) The inhibitory effect of bran on iron absorption in man. Am J Clin Nutr 34, 1469-1478.

15. Wang Y, Fun MA, Garleb KA, et al. (1994) The effect of fiber source in enteral products on fecal weight, mineral balance, and growth rate in rats. JPEN 18, 340-345.

16. Gralak MA, Leontowicz M, Morawiec M, et al. (1996) Comparison of the influence of dietary fiber sources with different proportions of soluble and insoluble fiber on $\mathrm{Ca}, \mathrm{Mg}, \mathrm{Fe}, \mathrm{Zn}, \mathrm{Mn}$ and $\mathrm{Cu}$ apparent absorption in rats. Arch Tierernahr 49, 293-299.

17. Bosscher D, Caillie-Bertrand MV \& Deelstra H (2001) Effect of thickening agents, based on soluble dietary fiber, on the availability of calcium, iron, and zinc from infant formulas. Nutrition 17, 614-618.

18. Bosscher D, Caillie-Bertrand MV, Cauwenbergh RV, et al. (2003) Availabilities of calcium, iron, and zinc from dairy infant formulas is affected by soluble dietary fibers and modified starch fractions. Nutrition 19, 641-645.

19. Catani M, Amancio OMS, Fagundes-Neto U, et al. (2003) Dietary cellulose has no effect on the regeneration of hemoglobin in growing rats with iron deficiency anemia. Braz J Med Biol Res 36, 693-697.

20. Freitas KC, Amancio OMS, Ferreira NN, et al. (2006) Partially hydrolyzed guar gum increases intestinal absorption of iron in growing rats with iron deficiency anemia. Clin Nutr 25, 851-858.
21. Feltrin C, Morais MB, Morais TB, et al. (2009) Effect of soluble fiber pectin on growth and intestinal iron absorption in rats during recovery from iron deficiency anemia. Biol Trace Elem Res 129, 221-228.

22. Green CJ (2002) Fibre in enteral nutrition: a new era. Nutr Hosp 17, Suppl. 2, S1-S6.

23. Silk DBA, Walters ER, Duncan HD, et al. (2001) The effect of a polymeric enteral formula supplemented with a mixture of six fibers on normal human bowel function and colonic motility. Clin Nutr 20, 49-58.

24. Schneider SM, Girard-Pipau F, Anty R, et al. (2006) Effects of total enteral nutrition supplemented with a multi-fibre mix on faecal short-chain fatty acids and microbiota. Clin Nutr 25, $82-90$.

25. Reeves PG, Nielse FH \& Fahey GC (1993) AIN-93 purified diets for laboratory rodents: final report of the American Institute of Nutrition ad hoc writing committee on the reformulation of the AIN-76A rodent diet. $J$ Nutr 123, 1939-1951.

26. Forbes AL, Adams CE, Arnaud MJ, et al. (1989) Comparison of in vitro, animal, and clinical determinations of iron bioavailability: International Nutritional Anemia Consultative Group Task Force report on iron bioavailability. Am J Clin Nutr 49, 225-238.

27. Borel MJ, Smith SH, Brigham DE, et al. (1991) The impact of varying degrees of iron nutritive on several functional consequences of iron deficiency in rats. J Nutr 121, 729-736.

28. Hugues PCR \& Tanner JM (1970) A longitudinal study of the growth of the black-hooded rat: methods of measurement and rates of growth for skull, limbs, pelvis, nose-rump and tail lengths. $J$ Anat 106, 349-370.

29. Wintrobe M, Mollin D, Herbert V, et al. (1968) Anemias nutricionales. Org Mund Salud Ser Inf Técn 405, 5-39.

30. Yokoi K, Konomi A \& Otagi M (2009) Iron biovailability of cocoa powder as determined by the $\mathrm{Hb}$ regeneration efficiency method. Br J Nutr 102, 215-220.

31. Rao J \& Jagadeesan V (1995) Development of a rat model for iron deficiency and toxicological studies: comparison among Fischer 344, Wistar, and Sprague Dawley strains. Lab Anim Sci 45, 393-397.

32. Freitas KC, Motta MEFA, Amâncio OMS, et al. (2004) The effect of soy polysaccharide fiber on fecal weight and humidity in growing rats. J Pediatr (Rio J) 80, 183-188.

33. Marks GE, Moore CE, Kanabrocki EL, et al. (1971) Determination of trace elements in human tissue. I. Cd, Fe, $\mathrm{Zn}, \mathrm{Mg}$ and Ca. Appl Spectrosc 26, 523-527.

34. Lopez HW, Levrat-Verny M, Coudray C, et al. (2001) Class two resistant starches lower plasma and liver lipids and improve mineral retention in rats. $J$ Nutr 131, 1283-1289.

35. Jandel (2005) Jandel SigmaStat 3.1. San Rafael, CA: Jandel.

36. Kanauchi O, Araki Y, Andoh A, et al. (2000) Effect of germinated barley food stuff administration on mineral utilization in rodents. J Gastroenterol 35, 188-194.

37. Cherbut $C$ (2002) Inulin and oligofructose in the dietary fiber concept. Br J Nutr 87, Suppl. 2, S159-S162.

38. Burkitt DP, Walker ARP \& Painter NS (1972) Effect of dietary fiber on stools and transit-times, and its role in the causation of disease. Lancet ii, 1408-1412. 